http://jmscr.igmpublication.org/home/

ISSN (e)-2347-176x ISSN (p) 2455-0450

crossref DOI: https://dx.doi.org/10.18535/jmscr/v8i6.120

IGM Publication

Journal Of Medical Science And Clinical Research

An official Publication of IGM Publication

\title{
Profile of Neurosurgical Emergencies in a Young Neurosurgical Centre in South-East Nigeria - A Three -Year Review
}

\author{
Authors \\ Ozor I.I ${ }^{*}$, Guga D.A ${ }^{2}$, Mezue W.C ${ }^{1,2}$, Chikani M.C ${ }^{1,2}$, Nevo A.C $C^{3}$ Nduagubam O.C ${ }^{4}$ Agwagu Z.N ${ }^{5}$ \\ ${ }^{1}$ Neurosurgery Unit, Department of Surgery, Enugu State University Teaching Hospital, Enugu, Nigeria \\ ${ }^{2}$ Neurosurgery Unit, Department of Surgery, University of Nigeria Teaching Hospital, Enugu \\ ${ }^{3}$ Department of Accident and Emergency, Enugu State University Teaching Hospital, Enugu, Nigeria \\ ${ }^{4}$ Department of Paediatrics, Enugu State University Teaching Hospital, Enugu, Nigeria \\ ${ }^{5}$ Department of Nursing Services, Enugu State University Teaching Hospital, Enugu, Nigeria \\ *Corresponding Author \\ Ozor Ignatius Ikemefuna
}

\begin{abstract}
Background/Purpose: This study was undertaken to determine the demographic and clinical profile of patients who presented toa young Neurosurgery service through the accident and emergency department in a tertiary hospital in south-east Nigeria.

Methods: A retrospective study of all consecutive neurosurgical patients admitted in the accident and emergency department of the Enugu State University Teaching Hospital (ESUTH), Enugu, Nigeria over the three-year period ending $31^{\text {st }}$ December, 2017. Admission records and patients' case notes were reviewed. Data were collected on proforma sheets designed for this study and analysed with SPSS version 20.0.

Results: Of the 495 surgical patients who presented to the accident and emergency department of the hospital within the period under review, 134 were neurosurgical patients, constituting $27.07 \%$ of all surgical emergencies seen. They were predominantly male $(M: F=3.5: 1)$, and their ages ranged from 1 to 86 years (mean $32.48 \pm 19.06$ years). Young patients 18 to 40 years old were the main age group affected, constituting $56 \%$ of the study population. Neuro-trauma accounted for $98.5 \%$ of cases - 118 (88.1\%) for head injury and 14 (10.4\%) for spine/spinal cord injury.

The month with the highest number of admissions was December, a month with increased road traffic activity by people travelling for Christmas celebrations and other end-of-year festivities.

Conclusion: Neuro-trauma remains a dominant neurosurgical emergency in Nigeria with a peak incidence in the festive month of December. Young people constitute the majority of victims, with a male preponderance. Measures targeted at reducing the incidence of road traffic crashes and consequent injuries, especially during festive periods would lessen the burden of neurosurgical emergencies.

Keywords: Head injury, Spinal cord injury, Motor vehicular crash, Festive period.
\end{abstract}

\section{Introduction}

Emergencies constitute a significant proportion of hospital surgical admissions ${ }^{[1],[2]}$. While the management of patients in emergency situations is primarily geared toward saving life and limiting morbidity, a lot of valuable data can be obtained from the patient profile as well as the day-to-day activities that take place in this department that 
could be utilised in shaping health care and other related policies as well as improving hospital services and patient outcomes.

In this study we sought to determine the demographic and clinical profile of neurosurgical patients that were admitted through the accident and emergency department and managed at the Enugu State University Teaching Hospital (ESUTH), Enugu, south-east Nigeria, within the 3-year period under review.

\section{Materials and Methods}

This was a retrospective study of all consecutive neurosurgical admissions into the accident and emergency department of the Enugu State University Teaching Hospital (ESUTH), Enugu, South-East Nigeria over the 3 -year period from $1^{\text {st }}$ January, 2015 to $31^{\text {st }}$ December, 2017. The Enugu State University Teaching Hospital is a 320 bed space hospital with neurosurgery constituting 23 only. It is situate at the centre of the city. The neurosurgical unit started active management of cases in January of the year 2016.

Admission records and patients' case notes were reviewed. Relevant demographic and clinical data of the study subjects were collected on structured proforma sheets designed for this study and analysed using the Statistical Package for Social Sciences (SPSS Inc., Chicago, IL, USA) version 20.0

\section{Results}

Of the 495 surgical patients who presented to the accident and emergency department of the hospital within the period under review, 134 were neurosurgical patients, constituting $27.07 \%$ of all surgical emergencies. Of these, 104 were male (77.6\%) and 30 female (22.4\%), giving a M:F ratio of 3.5:1. Their ages ranged from 1 to 86 years (mean $32.48 \pm 19.06$ years). Young patients, 18 to 40 years old were the predominant age group affected, constituting $56 \%$ of the study population.

The leading indications for admission were trauma-related. (Table)

Table: Distribution of patients by diagnosis on presentation

\begin{tabular}{|l|c|c|}
\hline Diagnosis & Number of patients & Percentage \\
\hline Head injury & 118 & 88.1 \\
\hline Spine/spinal cord injury & 14 & 10.4 \\
\hline Spontaneous subarachnoid haemorrhage & 2 & 1.5 \\
\hline Total & $\mathbf{1 3 4}$ & $\mathbf{1 0 0 . 0}$ \\
\hline
\end{tabular}

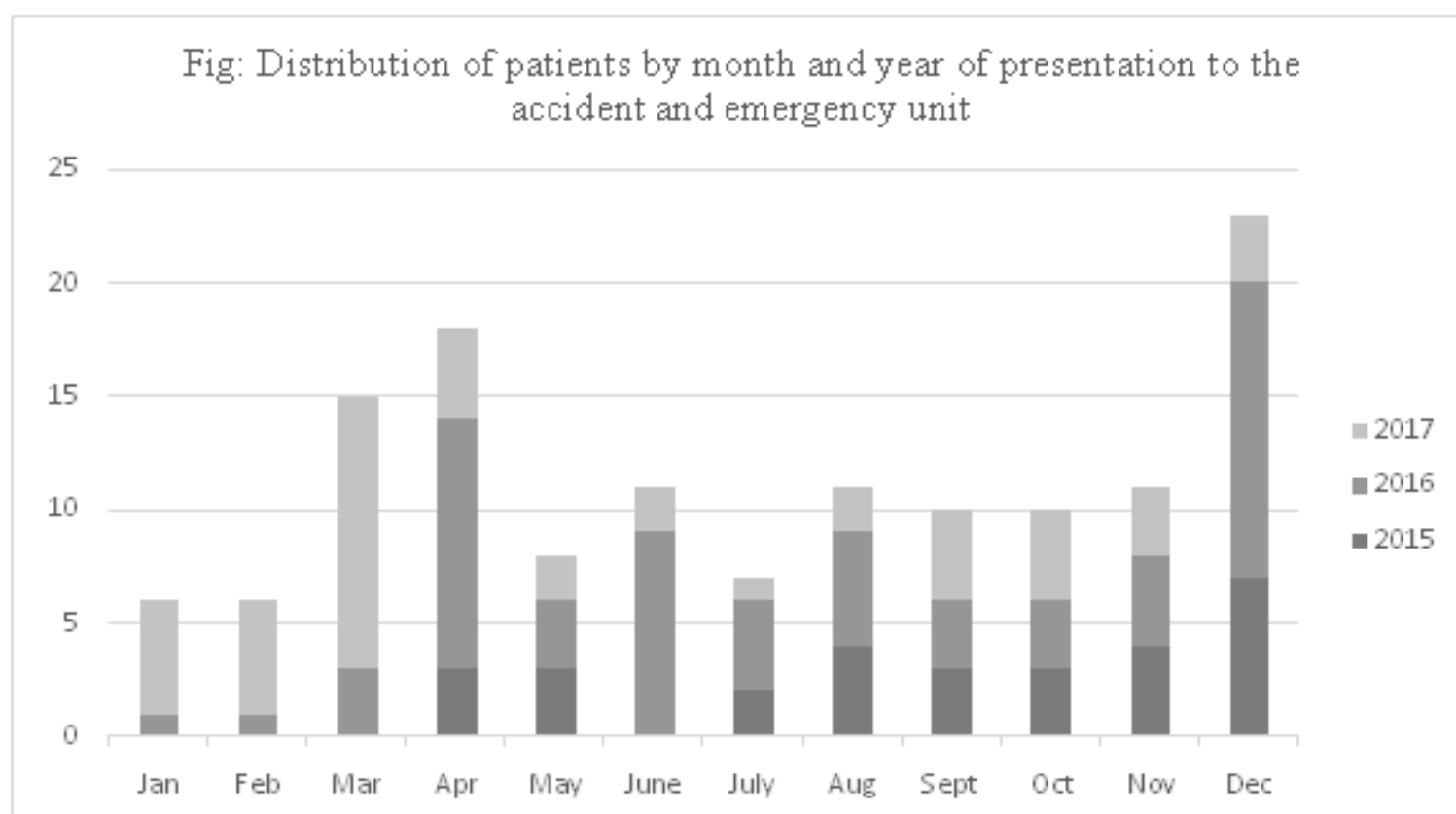


The month with the highest number of admissions was December (23), followed by April and March with 18 and 15 patients respectively (Fig).

Of the 134 admissions, 123 (91.8\%) were fully managed in the study centre, 8 were referred to other neurosurgical centres for further care, while 3 discharged themselves against medical advice. One hundred and twenty-seven patients were managed by the neurosurgical unit, while 5 were co-managed with other surgical/medical units for multiple injuries and/or co-morbid conditions.

\section{Discussion}

Neurosurgical patients constituted $27.07 \%$ of the surgical emergencies seen in the accident and emergency unit, highlighting the relative burden of emergency conditions that is constituted by neurosurgical diseases. In another report in Nigeria, neurosurgical emergencies accounted for $16 \%$ of the patients admitted into the surgery section of the accident and emergency centre ${ }^{[3]}$. Although a huge deficit still exists in the number of neurosurgeons who are catering for the huge Nigerian population, neurosurgical diseases cannot be said to be on a decline. The need for more personnel with the requisite training in this specialized service therefore remains pertinent. This might be even more so in remote areas where access to such specialized care is currently unavailable.

Neuro-trauma was overwhelmingly the leading neurosurgical indication for presentation at the accident and emergency department, with the majority of them being head injuries. Only 2 $(1.5 \%)$ were non-traumatic conditions. This typifies the huge burden that neuro-trauma constitutes in this environment. Nigeria belongs to the group of countries that meet only 0 or 1 of eight integrity vehicle standards ${ }^{[4]}$. The implication is that many vehicles on Nigerian roads could be unsafe. Road infrastructure which has been linked to the safety of road transport is also hugely deficient in terms of availability, design and maintenance as is the case in many low and middle-income countries ${ }^{[4],[5]}$. These factors, in addition to the poor enforcement of traffic rules and regulations regarding speed, seat-belt usage, child-restraint, helmet-usage among others, have kept road traffic injuries at the summit of neurosurgical emergencies in this country ${ }^{[4],[5]}$.

The patients in this study population were predominantly male $(\mathrm{M}: \mathrm{F}=3.5: 1)$. This is understandable, given that the leading diagnosis was head injury. Many studies have established the preponderance of males among patients with trauma of any kind, and with head injury in particular $^{[1],[6],[7]}$.

The young age of affected patients also correlates with findings from previous studies ${ }^{[1],[8]}$.The 2018 global status report on road safety identified road traffic injuries as the leading cause of death for children and young adults aged 5 to 29 years more deadly than HIV/AIDS, tuberculosis and diarrhea disease combined ${ }^{[4]}$. A number of factors have been adduced for the association between youth and the risk of road traffic injuries such as their relative naivety, high level of road usage, sensation-seeking tendencies while on the roads, peer influence, operating vehicles under the influence of alcohol and/or drugs and negligence of road safety measures ${ }^{[4],[6]}$.This demographic class can potentially be targeted with intervention measures aimed at addressing this problem.

The month with the highest number of admissions was December. A similar trend was documented by Abiona and colleagues, who in a time series analysis of admissions in the accident and emergency department of the University College Hospital Ibadan, Nigeria, reported peak numbers of patients in the last quarter of every year, attributable to an increase in travel rates for the end-of-year festivities, and the consequent increased risk of motor vehicular crashes and injuries ${ }^{[9]}$. This observation offers an opportunity to change the trend through a more thorough analysis of the factors that make road travel more risky in this time of the year, and instituting measures to tackle them.

The majority of neurosurgical emergencies admitted were fully managed in the study centre, 
with less than $10 \%$ requiring referral to another facility. This is in variance with what obtained a decade ago in the same institution. The change in trend is due to the availability of neurosurgeons in the centre now and the consequent experience that has been gained by trainees and other health workers over the last few years.

\section{Conclusion}

Neuro-trauma remains a dominant neurosurgical emergency in Nigeria with a peak incidence in the festive month of December. Young people constitute the majority of victims, with a male preponderance. Measures targeted at reducing the incidence of road traffic crashes and consequent injuries, especially during festive periods would lessen the burden of neurosurgical emergencies.

\section{Limitations}

The objectives of this study were achieved. However, being a single centre study, inferences from the results can only be made to a limited degree in the context of the entire Nigerian population. The findings however give some insight into the pattern of neurosurgical emergencies in a young neurosurgical centre in South-East Nigeria.

Source of Funding: We had no funding support in any form.

Competing Interests: No conflict of interest

\section{References}

1. Mai-Phan TA, Patel B, Walsh M, Abraham AT, Kocher HM. Emergency room surgical workload in an inner city UK teaching hospital. Worl J Emerg Surgey. 2008;3(19):1-7.

2. Onyemaechi NOC, Urube SU, Ekenze SO. Pattern of surgical emergencies in a Nigerian tertiary hospital. Afr Health Sci. 2019;19(1):1768-77.
3. Mofikoya BO, Enweluzo GO, Tijani KH, Ogunleye EO, Kanu OO. Emergency surgical services in a sub Saharan African country: Can we meet the needs? Eur J Sci Res. 2010;43(2):265-71.

4. WHO. Global status report on road safety 2018: Summary. World Health Organization. 2018. p. 1-18.

5. Onyemaechi N, Ofoma U. The Public Health Threat of Road Traffic Accidents in Nigeria: A Call to Action. Vol. 6, Ann Med Health Sci Res. 2016. p. 199-204.

6. Kourouma K, Delamou A, Lamah L, Camara BS, Kolie D, Sidikiba S, et al. Frequency, characteristics and hospital outcomes of road traffic accidents and their victims in Guinea: a three-year retrospective study from 2015 to 2017. BMC Public Health. 2019;19(1022):1-12.

7. Verma A, Verma S, Garg P, Godara R, Karwasra RK, Verma N. Surgical Emergencies in a Tertiary Care Hospital : A Brief Overview. Int J Contemp Med Res. 2016;3(3):648-51.

8. Chikani MC, Ozor II, Onyia EE, Guga D, Mezue W., Iloabachie I. Review of Clinico-Demographic Patterns and Profiling of the Determinants of Outcome of Neurological Surgery Admissions in an Intensive Care Unit: Preliminary Study. Int J Sci Res. 2018;7(11):1055-9.

9. Abiona TO, Adebowale SA, Fagbamigbe AF. Time Series Analysis of Admission in the Accident and Emergency Unit of University College Hospital, Ibadan, Southwestern Nigeria. Am J Comput Appl Math. 2012;2(1):1-9. 